\title{
Formação inicial e o repertório para teclado em grupo
}

\author{
Initial Training and Repertoire for Group Keyboard
}

\author{
Simone Marques Braga \\ Universidade Estadual de Feira de Santana, Feira de Santana, Bahia, Brasil. \\ moninhabraga@gmail.com
}

Resumo: 0 presente artigo apresenta algumas reflexões sobre o repertório desenvolvido no componente curricular Teclado e suas possíveis contribuições para a formação inicial de professores de música. Desenvolvido em aulas coletivas, parte do repertório é analisado e aplicado por meio de atividades realizadas no componente pertencente a matriz curricular do curso de Licenciatura em Música da Universidade Estadual de Feira de Santana. São objetos da análise três métodos: 1) Diorama de Cacilda Borges Barbosa (caderno preparatório); 2) 13 Pequenas Peças Brasileiras de Moema Craveiro Campos; 3) Miniaturas (peças para piano) de Maria da Graça Santos. Como resultado, verifica-se que o domínio de conhecimentos e práticas musicais é fundamental para o exercício docente na área, visto que o fazer musical é uma ferramenta essencial para o ensino de música. Todavia, o fazer musical deve ser ampliado a partir da articulação com saberes teóricos e pedagógicos musicais.

Palavras-chave: formação inicial; repertório; teclado em grupo.

Abstract: This paper presents some thoughts on the repertoire developed in the curricular component keyboard and their contributions to the initial training of music teachers. Developed in group lessons, part of this repertoire is analyzed and applied through activities performed in the component pertaining to curriculum of the Bachelor's Degree in Music at the State University of Feira de Santana. They are objects of analysis three methods: 1) Diorama - Cacilda Borges Barbosa (preparatory documents); 2) 13 Small Parts Brazilian -Moema Craveiro Fields; 3) Miniatures (piano pieces) - Mary Grace Santos. As a result, it appears that the domain knowledge and musical practices is critical to the teaching practice in the area, as the music making is an essential tool for music education. However, music making was extended from the joint with theoretical knowledge.

Keywords: initial training; repertoire; keyboard group.

Data de recebimento: 04/03/2016

Data de aprovação final: 04/04/2016 


\section{1 - Introdução}

A pós-modernidade caracteriza-se por grandes mudanças em diversas esferas como a economia, a política, a diversidade sócio-cultural, a difusão das redes sociais, os avanços científicos e tecnológicos, a (re) definição de valores, o crescimento demográfico, entre outros. Tais mudanças apresentam implicações no ensino musical, desde a ampliação de espaços de atuação à elaboração de propostas metodológicas e emergem novas exigências educativas, sobretudo, na formação de profissionais capacitados para atuar na área. Diante desta realidade é oportuno verificar as condições atuais desta formação e as interferências de componentes curriculares de caráter específico a exemplo dos que envolvem a prática musical.

Neste sentido, é por meio do repertório que muitas habilidades pedagógicas musicais são desenvolvidas como a prática de acompanhar, decodificar cifras e padrões rítmicos, além do desenvolvimento técnico instrumental. Nesta perspectiva, o presente artigo apresenta algumas reflexões sobre parte do repertório desenvolvido no componente curricular Teclado, pertencente a matriz curricular do curso de Licenciatura em Música da Universidade Estadual de Feira de Santana (UEFS), através da análise de três métodos: 1) Diorama de Cacilda Borges Barbosa (caderno preparatório); 2) 13 Pequenas Peças Brasileiras de Moema Craveiro Campos; 3) Miniaturas (peças para piano) de Maria da Graça Santos. Na análise também são contempladas as atividades desenvolvidas a partir do repertório selecionado.

\section{1 - A estrutura das aulas de Teclado}

Para as aulas do componente curricular Teclado no curso de Licenciatura em Música da UEFS são utilizados teclados eletrônicos e piano, as quais são explorados os recursos disponíveis em cada um dos instrumentos. Desta forma, a nomenclatura do componente curricular abrange a literatura instrumental para instrumentos de teclas e não se limita ao instrumento teclado eletrônico. 
BRAGA, Simone Marques. (2016) Formação inicial e o repertório para teclado em grupo. Per Musi. Ed. por Fausto Borém, Eduardo Rosse e Débora Borburema. Belo Horizonte: UFMG, n.33, p.116-129.

O uso do teclado possibilita a utilização dos recursos tecnológicos como mudança de registros, ritmos variados, facilidade de locomoção além de contemplar o uso de cifras, específicas da literatura para teclado. Já a utilização do piano, sobretudo, para os alunos de nível intermediário a avançado em instrumentos de teclas, promove $\mathrm{o}$ desenvolvimento técnico instrumental por meio de uma literatura específica para piano, ao contemplar independência entre mãos, leitura simultânea de claves, texturas variadas, uso dos pedais, controle sonoro, entre outros.

Um dos desafios presentes na estruturação do componente é a logística: número de professores versus número de estudantes versus número de instrumentos. Poucos instrumentos e professores, em descompasso com quantidade dos matriculados no curso. A consideração deste fator aponta para a adoção de aulas em caráter coletivo como uma estratégia eficaz.

O caráter da aula atende não apenas a esta logística, mas apresenta benefícios para o desenvolvimento discente por meio da execução instrumental em grupo tornando-se um importante recurso didático. De fato, ter o outro indivíduo para observar, trocar experiências e construir novas referências na aprendizagem, apresenta contribuições para o aprendizado no instrumento como o ouvir harmônico, o aprimoramento instrumental, práticas de acompanhamento e a ampliação de repertório.

Nesta perspectiva, SWANWICK (1994), afirma que o ensino em grupo pode ser considerado uma valiosa estratégia para o ensino instrumental, além de se transformar em uma importante ferramenta no processo de iniciação e de democratização do ensino instrumental. CRUVINEL (2005) também destaca as vantagens da utilização da interação na aprendizagem musical realizada em grupo e aponta para ações resultantes deste processo como a socialização, a cooperação, a motivação, o rendimento e o ambiente lúdico proporcionado.

Outro aspecto a ser destacado são as contribuições para a formação pedagógica musical a partir da participação em grupos musicais, seja como condutor, ouvinte ou executante, para oportunizar a compreensão dos mecanismos acerca da prática 
BRAGA, Simone Marques. (2016) Formação inicial e o repertório para teclado em grupo. Per Musi. Ed. por Fausto Borém, Eduardo Rosse e Débora Borburema. Belo Horizonte: UFMG, n.33, p.116-129.

musical coletiva, ao possibilitar um laboratório para observação de propostas metodológicas e para a condução didática.

\section{2 - 0 repertório e a formação pedagógica musical}

A escolha do repertório está associada aos objetivos do componente curricular e ao desenvolvimento das habilidades discentes pretendidas. SLOBODA (2000) defende que as habilidades a serem desenvolvidas não devem limitar-se as habilidades técnicas e motoras. Segundo o autor são necessárias também habilidades interpretativas que gerem diferentes performances expressivas de uma mesma peça de acordo com o que se quer comunicar de forma estrutural e emocional. Neste contexto, o aspecto afetivo também deve ser considerado.

De acordo com pesquisas sobre a seleção de repertório (TOURINHO, 1995; FIREMAN, 2006), a consideração do interesse do estudante também é um fator essencial para o desenvolvimento motivacional no processo de ensino e aprendizagem de um instrumento musical. Todavia, nem sempre o repertório que o estudante deseja é o mais apropriado para o seu nível, assim como pode ocorrer de não contemplar as habilidades necessárias para a sua formação pedagógica musical. Cabe ao professor o concenso de mesclar peças, escolhidas pelo estudante e acessíveis às suas habilidades, com peças e livros didáticos específicos para o aprendizado do instrumento, que permitam o desenvolvimento de habilidades, tanto musicais, relacionadas a aspectos interpretativos, estilísticos, técnicos, quanto a habilidades para a atuação pedagógica, relacionadas a transposição, acompanhamento, entre outros.

Outros fatores a serem considerados são as possibilidades de ampliação do repertório, que deverá ser desprovido de preconceitos, de caráter eclético, ao contemplar desde o erudito ao popular, do antigo ao moderno. Neste sentido, SWANWICK (2003) considera fundamental desenvolver habilidades musicais variadas que ultrapassem a execução, a exemplo da criação, apreciação, conhecimentos teóricos e técnicos. 
BRAGA, Simone Marques. (2016) Formação inicial e o repertório para teclado em grupo. Per Musi. Ed. por Fausto Borém, Eduardo Rosse e Débora Borburema. Belo Horizonte: UFMG, n.33, p.116-129.

Contudo, é importante considerar o desenvolvimento gradativo destas habilidades no processo de ensino aprendizagem.

O repertório selecionado poderá estar incluso em livros didáticos, popularmente chamados por métodos, criados especificamente para aulas coletivas ou adaptados para esta modalidade de ensino. Mas, por que adotar repertório voltado para piano solo em aulas coletivas? Justamente por considerar que as aulas se inserem em um curso de formação de professores de música, é necessário contemplar um repertório que aborde a diversidade musical presente na música brasileira, além de possibilitar o diálogo entre períodos e gêneros musicais variados, a exemplo da junção de peças folclóricas brasileiras com a inserção de elementos musicais característicos da música contemporânea.

Na ausência de métodos voltados para o ensino coletivo que abordem estes aspectos, parte do repertório apresentado e analisado a seguir, foi selecionado dentre obras para piano solo. Vale ressaltar, que a seleção foi desenvolvida com licenciandos sem experiência prévia na execução de instrumentos de teclas, aos quais tiveram acesso ao mesmo por meio de atividades variadas, que serão descritas a seguir.

\section{1 - A análise dos métodos}

Segundo BARROS (2008) alguns compositores como Lorenzo Fernandez (1897-1948), Heitor Villa Lobos (1887-1959), Francisco Mignone (1897-1986), contribuíram para a criação de obras com fins didáticos. Além do alto conteúdo musical, algumas destas obras apresentam objetivos para o desenvolvimento de habilidades específicas, além de resguardarem tradições de determinadas culturas. Das composições brasileiras com o mesmo propósito pedagógico destacam-se os métodos analisados neste artigo, quais sejam: 1) Diorama de Cacilda Borges Barbosa (caderno preparatório); 2) 13 Pequenas Peças Brasileiras de Moema Craveiro Campos; 3) Miniaturas (peças para piano) de Maria da Graça Santos. 
BRAGA, Simone Marques. (2016) Formação inicial e o repertório para teclado em grupo. Per Musi. Ed. por Fausto Borém, Eduardo Rosse e Débora Borburema. Belo Horizonte: UFMG, n.33, p.116-129.

Estes métodos tem em comum a finalidade de desenvolver habilidades técnicas instrumentais, além de abordar a música brasileira, desde a utilização de ritmos e gêneros típicos, a exemplo de chorinhos, a elementos melódicos familiares da nossa cultura como o uso do sistema modal na música nordestina. De acordo com ZORZETTI (2010, p.729) a utilização de peças que façam parte do contexto sócio-cultural dos estudantes tornam-se um elemento motivador no ensino instrumental:

A opção por música brasileira se deve ao fato de acreditarmos ser
importante que o material de ensino contenha temas relacionados ao
contexto a que se destina, isto é, que utilize uma linguagem
compreensível ao estudante e que o repertório tenha algum tipo de
ligação com seu universo, pois esses são aspectos que podem
despertar um maior interesse e funcionar como fatores de motivação.

Outro fator em comum é o nível de dificuldade das peças que, em sua grande maioria, se classificam do nível básico ao nível elementar. Segundo UZLER (1995) os elementos musicais que correspondem a esta transição de nível estão relacionados a conceitos de leitura da notação musical, habilidades técnicas e habilidades funcionais a exemplo da utilização simultâneas das claves de sol e de fá, exploração, sobretudo, da região central do teclado, uso de semínimas, mínimas, quiálteras, síncopes, notas duplas, acordes em blocos e quebrados, preparação para a execução da textura polifônica, certo grau de independência entre as mãos em relação às dinâmicas, articulação e textura, entre outros.

Já sobre o nível elementar, REIS (2000) defende que o estudante precisa desenvolver competências pianísticas que envolvem o senso rítmico, noções de fraseado, toque e articulação, definição de planos sonoros, percepção de organização estrutural, uso simples do pedal e percepção da dimensão estética musical. Tais competências correspondem a uma maturidade musical desejável para estudantes deste componente na graduação. Todavia, há particularidades a serem observadas entre os métodos analisados, ao contribuir com o desenvolvimento destas competências, conforme descrição a seguir:

1) Diorama de Cacilda Borges Barbosa (caderno preparatório): 
BRAGA, Simone Marques. (2016) Formação inicial e o repertório para teclado em grupo. Per Musi. Ed. por Fausto Borém, Eduardo Rosse e Débora Borburema. Belo Horizonte: UFMG, n.33, p.116-129.

Direcionada para piano e estudo de ritmo e som, a obra caracteriza-se pela organização por grau de dificuldade, através de uma série de peças progressivas que difundem a rítmica brasileira, voltada para o ensino instrumental de jovens e adultos.

\begin{abstract}
Existem muito poucos livros voltados para o aluno iniciante adulto, especialmente de autores brasileiros. Isso se deve ao fato das edições se dedicarem mais ao ensino de crianças. Tais livros utilizam de uma roupagem visual voltada para as crianças, com desenhos de bichos, brinquedos, partituras coloridas e com tamanho grande para facilitar a leitura para elas, e peças com temas e títulos infantis. [...] Assim sendo, o Diorama oferece ao professor de piano uma opção de repertório que pode ser trabalhado com jovens e adultos, pelo fato de não utilizar desenhos nem figuras e pela temática (BARROS, 2008, p.3).
\end{abstract}

Por se tratar de um componente curricular direcionado para adultos, o método contribui para a aproximação com esta faixa etária, sobretudo, por estimular o desenvolvimento da musicalidade desde o princípio, que não induz em nenhum momento à leitura fragmentada, através de indicações de fraseado, com melodias simples, porém musicais, com uma textura de melodia acompanhada de fácil entendimento e escuta, e que trabalha a percepção de blocos contrastantes (BARROS, 2008). Tais características auxiliam a execução em planos sonoros diferenciados e, consequentemente, da experimentação e exploração do uso do pedal.

A estética dos estudos incentiva a análise harmônica, bem como o desenvolvimento de ritmos brasileiros através da utilização de síncopes e contratempos. Segundo BARROS (2008) a beleza consiste na presença da tradição carioca, com larga utilização do contraponto e a melódica do chorinho, somada ao tratamento em que a melodia passeia entre as mãos, nas claves de sol e de fa, ao induzir o desenvolvimento do deslocamento das mãos no teclado, independência entre mãos e o controle sonoro. 0 controle se consolida na tentativa da execução mais expressiva das peças do método.

Com este método foram contempladas peças específicas para cada estudante, para trabalhar particularidades e habilidades pessoais, e uma peça abordada coletivamente, aos quais todos executaram. Com esta peça, foram desenvolvidas as seguintes atividades: 
BRAGA, Simone Marques. (2016) Formação inicial e o repertório para teclado em grupo. Per Musi. Ed. por Fausto Borém, Eduardo Rosse e Débora Borburema. Belo Horizonte: UFMG, n.33, p.116-129.

\begin{tabular}{|c|c|c|}
\hline Peça contemplada & Atividade & Objetivo \\
\hline Estudo $n^{\circ} 59$ & $\begin{array}{l}\text { Execução e criação de uma } \\
\text { introdução musical }\end{array}$ & $\begin{array}{l}\text { Desenvolver a habilidade de } \\
\text { criação e execução }\end{array}$ \\
\hline Estudo $n^{\circ} 59$ & $\begin{array}{lr}\text { Análise } & \text { musical } \\
\text { (tonalidade; } & \text { período; } \\
\text { fraseologia; } & \text { possibilidades } \\
\text { de dinâmica) } & \\
\end{array}$ & $\begin{array}{ll}\text { Desenvolver } \\
\text { musicais }\end{array}$ \\
\hline Estudo $n^{\circ} 59$ & $\begin{array}{l}\text { Identificação e execução do } \\
\text { registro escrito da célula } \\
\text { rítmica do choro }\end{array}$ & $\begin{array}{l}\text { Reconhecer e executar padrão } \\
\text { de acompanhamento rítmico } \\
\text { de choro }\end{array}$ \\
\hline Estudo $n^{\circ} 59$ & $\begin{array}{l}\text { Harmonização da peça } \\
\text { através da utilização de } \\
\text { cifras alfabéticas }\end{array}$ & $\begin{array}{l}\text { Desenvolver a habilidade de } \\
\text { harmonizar, classificar e } \\
\text { construir acordes, decodificar } \\
\text { e reconhecer cifras }\end{array}$ \\
\hline Estudo $n^{\circ} 59$ & $\begin{array}{l}\text { Acompanhamento } \\
\text { harmônico com o padrão de } \\
\text { choro para a execução da } \\
\text { peça executada por pares }\end{array}$ & $\begin{array}{l}\text { Desenvolver a habilidade para } \\
\text { acompanhamento por meio de } \\
\text { cifras e padrões de rítmicos de } \\
\text { acompanhamentos }\end{array}$ \\
\hline
\end{tabular}

Figura 1: Quadro das atividades da peça Estudo no 59

\section{2) 13 Pequenas Peças Brasileiras de Moema Craveiro Campos:}

O livro apresenta uma coletânea de peças curtas para piano solo compostas a partir de diversos gêneros brasileiros como a bossa-nova, baião, modinha, entre outros. Segundo CAMPOS (2002, p.5) ao oferecer-lhes

[...] ritmos que naturalmente já estão nos seus 'ouvidos'[...] daria a eles a chance de desenvolver a leitura de alguns padrões rítmicos que, embora pareçam difíceis, são parte de nossa raiz [...] Cada peça representa um gênero diferente, explicitado por títulos como: Baião Mulato, Choro de Criança, Sertaneja, Nova Bossa, Nova Modinha, dentre outros.

Justamente o conhecimento prévio discente dos gêneros abordados como referência promoveu a motivação dos mesmos em aprender e apreender tais gêneros, por meio da execução musical. No processo da aprendizagem das peças, notou-se que a articulação entre a percepção auditiva com a leitura musical, possibilitou uma execução musical fluente.

Esta percepção discente também foi incentivada através da utilização do CD que acompanha o livro. Além de trazer todas as peças interpretadas pela autora, contempla 
explicações técnicas e estéticas para a interpretação de cada uma. Além deste apoio pedagógico por meio do incentivo a percepção auditiva e da utilização de gêneros brasileiros diversos, as linhas melódicas traduzem a musicalidade brasileira através da construção simples das mesmas.

Nas composições não há citações de temas folclóricos ou populares brasileiros, entretanto, há um cuidado em resgatar características melódicas presentes nos diversos gêneros musicais, a exemplo do uso de células rítmicas sincopadas, uso de modos, entre outros, com o objetivo de "usar a riqueza da música brasileira para motivá-los" (CAMPOS, 2002, p.5).

Das 13 peças presentes no livro, a Cantoria nas Teclas foi a selecionada para ser ensinada e executada coletivamente, através das seguintes atividades:

\begin{tabular}{|l|l|l|}
\hline \multicolumn{1}{|c|}{ Peça contemplada } & \multicolumn{1}{|c|}{ Atividade } & \multicolumn{1}{|c|}{ Objetivo } \\
\hline Cantoria nas Teclas & Identificação dos modos & $\begin{array}{l}\text { Desenvolver a habilidade de } \\
\text { reconhecer e construir modos }\end{array}$ \\
\hline Cantoria nas Teclas & $\begin{array}{l}\text { Realização de pesquisa de } \\
\text { tipos de músicas } \\
\text { nordestinas }\end{array}$ & $\begin{array}{l}\text { Reconhecer e promover a } \\
\text { aproximação a tipos de } \\
\text { músicas pertencentes ao } \\
\text { repertório nordestino }\end{array}$ \\
\hline Cantoria nas Teclas & $\begin{array}{l}\text { Execução da peça sugerindo } \\
\text { possibilidades do uso do } \\
\text { pedal e da inserção de } \\
\text { dinâmicas }\end{array}$ & $\begin{array}{l}\text { Desenvolver a habilidade de } \\
\text { explorar e discutir as } \\
\text { possibilidades de planos e } \\
\text { controle sonoro }\end{array}$ \\
\hline Cantoria nas Teclas & $\begin{array}{l}\text { Análise musical (período; } \\
\text { fraseologia; textura) }\end{array}$ & $\begin{array}{l}\text { Desenvolver } \\
\text { musicais }\end{array}$ \\
\hline Cantoria nas Teclas & $\begin{array}{l}\text { Criação musical em um } \\
\text { modo escolhido pelo } \\
\text { licenciando }\end{array}$ & $\begin{array}{l}\text { Promover a aproximação e } \\
\text { conhecimento dos modos }\end{array}$ \\
\hline Cantoria nas Teclas & $\begin{array}{l}\text { Identificação dos conteúdos } \\
\text { musicais que poderão ser } \\
\text { abordados na Cantoria nas } \\
\text { Teclas para aulas de música } \\
\text { e para a criação discente }\end{array}$ & $\begin{array}{l}\text { Identificar conteúdos musicais } \\
\text { a serem explorados }\end{array}$ \\
\hline
\end{tabular}

Figura 2: Quadro das atividades da peça Cantoria nas Teclas

3) Miniaturas (peças para piano) de Maria da Graça Santos: 
BRAGA, Simone Marques. (2016) Formação inicial e o repertório para teclado em grupo. Per Musi. Ed. por Fausto Borém, Eduardo Rosse e Débora Borburema. Belo Horizonte: UFMG, n.33, p.116-129.

Lançado em 2004, pela Editora da Universidade Federal da Bahia (Edufba), instituição ao qual a compositora baiana exerceu atividades de ensino, o livro contém 68 pequenas peças. Datadas de 1967, 1980, 1986, 1992, 2000 e 2001, das miniaturas, conforme denomina a compositora, 29 são de autoria completa e 39 versões oriundas do folclore brasileiro.

Das 29 composições originais, é nítida a influência do compositor Béla Bartók por meio da exploração de determinados aspectos técnicos, a exemplo da imitação, movimento contrário, ostinato, temas melódicos alternados entre as mãos, temas com pequenas variações, síncopes, contratempos, mudança de compassos, baixo com notas repetidas e a utilização do sistema modal. Possibilitar o desenvolvimento e a execução destes aspectos torna-se o principal objetivo desta parte do livro.

Já na segunda parte, encontram-se as versões de peças oriundas do folclore brasileiro. Nesta parte, um dos principais objetivos é o de difundir peças pouco conhecidas, ao promover a aproximação dos executantes e ouvintes a raízes musicais brasileiras. Sobre as versões, destaca-se o diálogo presente entre a tradição musical, por meio dos temas folclóricos, e a inovação em fazer uso de aspectos da música contemporânea, a exemplo do sistema serial, acordes dissonantes e exploração variada de texturas musicais.

Sobre o uso do pedal, a compositora argumenta que a pedalização é dispensável, uma vez que sugere que seja priorizado um "som mais puro na execução e que tal som, tanto quanto possível, não seja dependente do pedal" (SANTOS, 2004, p.8). Todo este conjunto de elementos musicais torna o grau de dificuldade do álbum mais complexo em detrimento dos outros analisados. Ao executante é necessário certo grau de habilidade pianística e maturidade musical, tanto para escolher dedilhados que favoreçam a execução das articulações solicitadas, como também para realizar todos estes elementos com fluência musical.

Com relação as letras das músicas folclóricas, SANTOS (2004) defende que melodias com letras possibilitam uma melhor compreensão de rítmos e que as repetições 
BRAGA, Simone Marques. (2016) Formação inicial e o repertório para teclado em grupo. Per Musi. Ed. por Fausto Borém, Eduardo Rosse e Débora Borburema. Belo Horizonte: UFMG, n.33, p.116-129.

musicais com pequenas variações ajudam no desenvolvimento da leitura e na memorização. Apesar de ser uma composição para piano solo, a versão de Ciranda, Cirandinha foi selecionada para ser trabalhada coletivamente, através do desenvolvimento das seguintes atividades:

\begin{tabular}{|c|c|c|}
\hline Peça contemplada & Atividade & Objetivo \\
\hline Ciranda, Cirandinha & $\begin{array}{l}\text { Identificação das texturas } \\
\text { musicais }\end{array}$ & $\begin{array}{lcr}\text { Verificar } & \text { a compreensão } \\
\text { discente } & \text { referente a textura } \\
\text { musical } & & \end{array}$ \\
\hline Ciranda, Cirandinha & $\begin{array}{l}\text { Pesquisa e apresentação de } \\
\text { Seminário sobre peças por } \\
\text { imitação e contrapontísticas }\end{array}$ & $\begin{array}{lcr}\text { Verificar a compreensão } \\
\text { discente sobre peças por } \\
\text { imitação e contrapontísticas }\end{array}$ \\
\hline Ciranda, Cirandinha & $\begin{array}{l}\text { Identificação de tonalidade, } \\
\text { linha melódica } \\
\text { acompanhamento }\end{array}$ & $\begin{array}{lrrr}\text { Verificar a capacidade } & \text { de } \\
\text { identificação } & \text { de elementos } \\
\text { musicais } & \text { específicos } & \text { na } \\
\text { partitura } & & \end{array}$ \\
\hline Ciranda, Cirandinha & $\begin{array}{l}\text { Execução da peça sugerindo } \\
\text { possibilidades do uso do } \\
\text { pedal, articulações e da } \\
\text { inserção de dinâmicas }\end{array}$ & $\begin{array}{l}\text { Desenvolver a habilidade de } \\
\text { explorar e discutir as } \\
\text { possibilidades de planos e } \\
\text { controle sonoro } \\
\text { Desenvolver independência } \\
\text { entre mãos } \\
\text { Verificar a execução das } \\
\text { articulações legato e stacato }\end{array}$ \\
\hline Ciranda, Cirandinha & Harmonização e cifragem & $\begin{array}{l}\text { Desenvolver habilidade de } \\
\text { harmonização e decodificação } \\
\text { de cifras }\end{array}$ \\
\hline Ciranda, Cirandinha & $\begin{array}{l}\text { Leitura do texto: } \\
\text { A Literatura pianística do } \\
\text { século XX para o ensino do } \\
\text { piano nos níveis básico e } \\
\text { intermediário, de Ingrid } \\
\text { Barancoski }\end{array}$ & $\begin{array}{l}\text { Discussão } \quad \text { sobre } \\
\text { características de peças para } \\
\text { piano contemporâneas }\end{array}$ \\
\hline Ciranda, Cirandinha & $\begin{array}{l}\text { Elaboração de um plano de } \\
\text { aula ao qual a música seja } \\
\text { abordada e direcionada } \\
\text { para a Educação Básica }\end{array}$ & $\begin{array}{l}\text { Discutir sobre a visão discente } \\
\text { do ensino de música na escola } \\
\text { Desenvolver a habilidade de } \\
\text { elaboração de planos de aula }\end{array}$ \\
\hline
\end{tabular}

Figura 3: Quadro das atividades da peça Ciranda, Cirandinha

\section{3 - Considerações finais}

Da análise dos métodos apresentada, nota-se a riqueza musical presente em ambos. Desta riqueza, vale ressaltar a capacidade em um só momento de contemplar o desenvolvimento de aspectos técnicos, motores, estéticos e culturais em concordância 
BRAGA, Simone Marques. (2016) Formação inicial e o repertório para teclado em grupo. Per Musi. Ed. por Fausto Borém, Eduardo Rosse e Débora Borburema. Belo Horizonte: UFMG, n.33, p.116-129.

com a literatura consultada (REIS, 2002; SWANWICK, 2003; SLOBODA, 2000). Por serem concebidos especificamente para a utilização em aulas de instrumentos, há todo um cuidado na seleção e progressão dos elementos musicais abordados, assim como no estabelecimento de um diálogo com tradições musicais brasileiras, que refletem em uma execução musical mais fluente em função a aproximidade discente como os gêneros brasileiros contemplados.

0 fato de explorar elementos pertencentes à cultura brasileira e a música contemporânea, já contribuem para a formação inicial de professores de música, visto que possibilita o acesso discente a um repertório variado e, consequentemente, a práticas musicais diferenciadas. Ao vivenciar e ter como referência em sua formação um repertório variado cria-se condições para uma abertura futura, enquanto docentes, para contemplação da diversidade no ensino de música. No entanto, paralelo a estas influências, é necessário que componentes do eixo prático musical, pertencentes a matriz curricular de cursos de licenciatura, promovam ações com a intencionalidade de contribuir com a formação pedagógica musical. Neste sentido, no relato da experiência vivenciada na UEFS, destacam-se as atividades desenvolvidas a partir do repertório selecionado.

Inicialmente, o planejamento das atividades voltadas para o ensino coletivo favoreceu a formação pedagógica musical a partir do desenvolvimento de competências para o trabalho em equipe, como o respeito ao outro e o convívio com divergências de opiniões, pontos de vistas e nível técnico musical. Este desenvolvimento criou condições didáticas para lidar com grupos, visto que nem todos os licenciandos possuíam a experiência prévia na execução instrumental coletiva.

Outras contribuições para a formação pedagógica foram ações voltadas para o desenvolvimento de habilidades necessárias para a atuação docente a exemplo da capacidade de refletir sobre o ensino de música na escola e as possibilidades de utilização dos conhecimentos aprendidos e apreendidos no componente curricular Teclado neste contexto, além de desenvolver a habilidade de planejar aulas de música, 
BRAGA, Simone Marques. (2016) Formação inicial e o repertório para teclado em grupo. Per Musi. Ed. por Fausto Borém, Eduardo Rosse e Débora Borburema. Belo Horizonte: UFMG, n.33, p.116-129.

ao identificar conteúdos musicais a serem explorados nas peças estudadas e aplicados em aulas de música por meio da elaboração de planos de aula.

Com relação a aspectos musicais, as atividades contemplaram fatores significativos para o desenvolvimento da formação instrumental, ao abranger desde elementos técnicos a elementos estéticos/expressivos. 0 domínio de conhecimentos e práticas musicais é fundamental para o exercício docente na área, visto que o fazer musical é uma ferramenta essencial para o ensino de música. Todavia, é importante que o fazer musical seja ampliado a partir da articulação com saberes teóricos por meio de atividade de discussão, leitura de textos, apresentação de seminários, entre outros.

Sobre esta articulação, nota-se ser uma estratégia possível de ser adotada em componentes curriculares de caráter prático inseridos em cursos de licenciatura em música. A estratégia, que reside na seleção do repertório e nas atividades aplicadas a partir do mesmo, aponta para ações a serem desenvolvidas em consonância com os paradigmas sociais da pós-modernidade e suas influências na formação e atuação de profissionais da área de Educação Musical.

\section{Referências}

1. BARANCOSKI, I. A Literatura pianística do século XX para o ensino do piano. Per Musi, v.9, 2004, p.89-113.

2. BARROS, L. B. (2008). “O potencial pedagógico do volume preparatório da obra Diorama para piano de Cacilda Borges Barbosa”. Monografia (Graduação). Curso de Licenciatura do Instituto Villa-Lobos, Rio de Janeiro.

\section{CRUVINEL, F. M. (2005). Educação musical e transformação social - uma} experiência com ensino coletivo de cordas. Goiânia: Instituto Centro-Brasileiro de Cultura.

4. FIREMAN, M. C. (2006). “O repertório na aula de violão: um estudo de caso”. 2006. 150 f. Dissertação (Mestrado em Música). Escola de Música, Universidade Federal da Bahia, Salvador, Bahia.

5. REIS, C. S. (2000). "A obra de Lorenzo Fernandes e a aprendizagem pianística na infância”. Dissertação (Mestrado). Universidade Federal de Minas Gerais, Belo Horizonte. 
BRAGA, Simone Marques. (2016) Formação inicial e o repertório para teclado em grupo. Per Musi. Ed. por Fausto Borém, Eduardo Rosse e Débora Borburema. Belo Horizonte: UFMG, n.33, p.116-129.

6. SWANWICK, Keith. "Ensino instrumental enquanto ensino de música". Cadernos de Estudo: Educação Musical. São Paulo: Atravez, n. 4/5, p.7-14, 1994.

7. (2003). "Ensinando música musicalmente". Trad.: Alda Oliveira e Cristina

Tourinho. São Paulo: Moderna.

8. SLOBODA, J. A. (2000). "Individual differences in music performance". Trends in Cognitive Sciences. vol. 4, n. 10, Oct., p.397-403.

9. TOURINHO, A. C. G. S. (1995). "A motivação escolar na aula de violão em grupo: influência do repertório de interesse do aluno". Salvador: Dissertação de Mestrado, Universidade Federal da Bahia.

10. USZLER, M.; GORDON, S.; MACH, E. (1995). The well-tempered keyboard teacher. New York: Schirmer Books.

11. ZORZETTI, D. (2010). "Música brasileira para o ensino do piano no nível elementar". I Simpósio Brasileiro de Pós-Graduandos em Música e XV Colóquio do Programa de Pós-Graduação em Música da UNIRIO. Anais... Rio de Janeiro, 8 a 10 de novembro.

\section{Referências de partituras}

1. BARBOSA, C.B. (1988). In: Diorama - caderno preparatório, Rio de Janeiro. p.39.

2. CAMPOS, M. C. (2002). In: 13 pequenas peças brasileiras. São Paulo: Irmãos Vitale. p.12.

3. SANTOS, M. G. (2004). In: Miniaturas: peças para piano. Salvador: Edufba. p.9.

Nota sobre a autora

Simone Marques Braga possui Bacharelado em Piano (Habilitação em Piano Conservatório Brasileiro de Música Centro Universitário-1994), Licenciatura em Educação Artística (Hab. em Musica - Conservatório Brasileiro de Música Centro Universitário-1996), Especialização em Artes (UNEB/IAT - 2004), Especialização em Regência Coral e Docência Superior (UNASP Centro Universitário - 2006), Mestrado em Educação Musical (UFBA - 2009) e Doutorado em Educação Musical (2010 - 2014). Professora Adjunta da Universidade Estadual de Feira de Santana (UEFS), coordenadora do Subprojeto de Música PIBID da UEFS e uma das líderes do Grupo de Estudos Contemporâneos em Música. 